Running head: YOUNG ADOLESCENTS' REPORTING OF ONLINE RISKS

Influence of age, gender and personality on young adolescents' reporting of online risks to third parties

\author{
Gordon P. D. Ingram
}

Universidad de los Andes, Colombia 


\begin{abstract}
Young people's exposure to various types of risk on the Internet-including interactions with strangers, inappropriate material, and cyberbullying - is an increasing social concern. Exposure to online risks has been found to increase with age and to correlate with certain personality characteristics. However, adolescents' own reporting to adults of the risks that they encounter has been much less studied, even though effective communication about online risks is vital to help young people manage them. A survey on online risks, along with a short Big Five personality test (the TIPI), was administered to 193 Colombian adolescents (101 female), aged between 12-15 years and in 7th or 9th grade. Age-related hypotheses were that exposure to online risks and online conflicts would rise between 7 th and 9 th grade, while reporting of risk exposure to adults would fall. The age-related hypotheses were supported: 9th-graders were exposed to significantly more online risks and participated in significantly more online conflicts than 7th-graders, while reporting such incidents significantly less often to adults (both parents and teachers). However, the only personality-based hypothesis to be firmly supported was that extraversion would be associated with more reporting of online risks. Multiple regression further showed that demographic factors (age and gender) taken together explained significantly more of the variation in online risk exposure, conflict participation and risk reporting than did all personality factors together. Results suggest that young people undergo increased exposure to online risks and conflicts in early-to-middle adolescence, accompanied by a reduction in reporting of such incidents to adults.
\end{abstract}

Keywords: communication with adults; gender differences; online risks; personality 


\section{Influence of age, gender and personality on young adolescents' reporting of online risks to third parties}

In recent years access to the Internet among adolescents, particularly via smartphones, has increased dramatically, with $95 \%$ or more of teenagers in high-income countries such as the USA having access to a smartphone, and $45 \%$ saying they are "constantly" using the Internet (Schaeffer, 2019). As Internet access has increased, so has concern among parents and schools about the risks to which adolescents are exposed online, including in emerging economies where over $50 \%$ of adults now have smartphones, and almost $80 \%$ are "very concerned" about the effects on children of accessing risky content on phones (Silver et al., 2019). This concern has its roots in three main phenomena: firstly, a supposed greater propensity of adolescents to engage in risky behavior of various forms (including delinquency, risky sexual behavior, and substance abuse); secondly, a recognition that adolescents are using smartphones more frequently than adults (especially those of their parents' generation or older), often in ways that parents or teachers fail to track or fully understand; and thirdly, a feeling that in their naivety about other people's motivations, children and adolescents are particularly vulnerable to exploitation by adults who engage in behaviors such as "grooming", adding to their sexual risks in particular.

Risks for this age group can be divided into two types. On the one hand, there are general "internal" risks from over-use of the Internet (and social media in particular) potentially leading to problems like depression, anxiety, loneliness, negative body image, and a feeling of addictedness. On the other are "external" risks associated with particular forms of risky content — including graphically sexual or violent material—or risky interactions with others, which can involve either invasions of privacy, such as soliciting 
personal details or sexual images (Baumgartner, Valkenburg, \& Peter, 2010; Livingstone \& Görzig, 2014) or interpersonal conflicts such as occur in cyberbullying.

Naturally, both internal and external risks are heterogeneous to a great extent, and changes in their frequency may be explained by quite diverse factors. Yet there are some common themes, especially in the second group of external risks that form the focus of the current study. Exposure to all forms of online risks increases with age up to adulthood (Cabello-Hutt, Cabello, \& Claro, 2018), in part because older adolescents are simply using the Internet more, but also perhaps because they are experimenting more with their own preferences and are less subject to adult restrictions on their online behavior. Risky sexual behavior in response to sexual risks may also increase, again for the latter two reasons (Baumgartner et al., 2010). In contrast, cyberbullying and other conflict-related behavior online may decrease slightly between middle and later adolescence (Antoniadou \& Kokkinos, 2015; Gibb \& Devereux, 2014; Kircaburun et al., 2019), related to a general decrease in interpersonal conflict as young people reach adulthood and improve their conflict-management skills (Ingram, 2013). Gender also has a part to play, with much evidence that girls are more exposed to sexual risks (in the form of unwelcome sexual advances) online than boys are, while possibly being less likely to act on them, at least if frequency of risk exposure is controlled for (Baumgartner et al., 2010). Evidence for the effect of gender on cyberbullying and online conflict is much more mixed, with some studies finding more conflict among girls, others finding more among boys, and still others finding no significant gender differences (Sun, Fan, \& Du, 2016), a balance of results that may be suggestive of an important role for locally variable peer-group norms.

In addition to age and gender, personality has been examined as a possible source of variation in both exposure to risk and risky behavior. The trait most investigated has been 
sensation-seeking, which has been found to be associated with sexting (Van Ouytsel, Van Gool, Ponnet, \& Walrave, 2014), receiving sexual messages (Livingstone \& Görzig, 2014), online gaming addiction (Hu, Zhen, Yu, Zhang, \& Zhang, 2017; Mehroof \& Griffiths, 2010), online deception (Lu, 2008), online gambling (White, Gummerum, \& Hanoch, 2018), risky self-presentation (Koutamanis, Vossen, \& Valkenburg, 2015), pornography usage (Beyens, Vandenbosch, \& Eggermont, 2015), and meeting online contacts in offline contexts (Bayraktar, Barbovschi, \& Kontrikova, 2016).

However, it might seem almost tautologous to say that sensation-seeking is linked to exposure to risks online (since risky behavior tends to cause exciting sensations, and exposure often informs some form of active seeking). Perhaps partly for this reason, other authors have looked for relationships between more general personality traits (such as the “Big Five”) and internet usage. For example, Öztürk, Bektas, Ayar, Öztornacı, and Yağcı (2015) found higher rates of extraversion and openness to experience in those participants at risk of internet addiction. Meanwhile, sexting has been associated with high extraversion and low conscientiousness (Gámez-Guadix \& De Santisteban, 2018). These results contrast with an earlier study by Kuss, van Rooij, Shorter, Griffiths, and van de Mheen (2013) which found extraversion (along with conscientiousness) to be a preventive factor against online gaming addiction, and one by Van der Aa and colleagues (2019) which found associations between compulsive internet use and introversion (along with low agreeability). Finally, the relative contributions of sensation-seeking and broader "Big Five" personality traits to online gambling among adolescents were directly compared by Reardon, Wang, Neighbors, and Tackett (2019) who showed that low levels of conscientiousness and high levels of sensation-seeking formed separate routes to problematic gambling in their participants. 
Running head: YOUNG ADOLESCENTS' REPORTING OF ONLINE RISKS

Individual characteristics such as age, gender and personality are not the only factors that may affect exposure to risks online. A substantial literature has examined the effects of parental mediation on teenager's internet use, with a view to finding out what is the best mediation strategy for parents to take in order to protect their children from risks. In particular, it has been debated whether it is better for parents to take a restrictive mediation strategy to limit internet use by teenage children, or a more active, enabling strategy which co-constructs a form of internet usage with children (Ho, Chen, \& $\mathrm{Ng}$, 2017). The large-scale EU Kids Online study found that restrictive strategies tend to be favored when parents' or children's digital skills are lower, and enabling strategies when they are higher, with enabling strategies increasing the risks but also the opportunities associated with internet use (Livingstone et al., 2017). A similar double-edged pattern of restrictive strategies lowering both risks and opportunities was reported recently from Brazil (Cabello-Hutt et al., 2018). In Singapore, Shin and Lwin (2017) found that active mediation by parents and teachers reduced the level of risk that participants encountered, whereas that by peers raised it. Mediation by parents also declined during adolescence, while peer mediation increased. Meanwhile, Ho and colleagues (2017) found that restrictive mediation worked better for primary school pupils than for secondary school pupils.

However, almost all of this literature has focused on mediation defined in terms of adults (or occasionally peers) talking to teenagers about how the latter should manage their internet use: very little research has examined how teenagers proactively report the risks that they encounter online or the activities that they carry out there. An important exception is the innovative diary study of parent-adolescent pairs by Wisniewski, Xu, Rosson, and Carroll (2017), which found that parents consistently underestimated not only their teenage 
Running head: YOUNG ADOLESCENTS' REPORTING OF ONLINE RISKS

children's exposure to risks online, but also their vulnerability to risk (in terms of propensity to respond in risky ways), while overestimating their willingness to report the risks that they had encountered. It thus appears critical to better understand adolescents' communication with parents and other adults about the risks that they face online.

\section{Hypotheses}

The hypotheses in this study concerned how the dependent variables of risk exposure, risk reporting, online conflict, and concern about online risks were influenced by the independent variables of age, gender and personality. The studies in the literature review show that exposure to risks on the Internet increases as children move through adolescence, and is higher for girls who may be more targeted by predatory adults. It may also be higher for individuals who are open to experience. Therefore, I predicted that: H1: Age (H1A), female gender (H1B) and openness to experience (H1C) all positively influence exposure to risks online.

On the other hand, whether an individual's actions leave them open to online risks - their level of risk vulnerability - is likely to be affected by gender (girls tend to be more riskaverse than boys) and by conscientiousness. With increasing age through adolescence, on the other hand, individuals become both more curious about risky material more confident of their ability to manage risks independently, and therefore may be more likely to act in a way that leaves them more vulnerable. Thus, I predicted that:

H2: Age (H2A) positively affects vulnerability to risk while female gender $(\mathrm{H} 2 \mathrm{~B})$ and conscientiousness (H2C) negatively influence it.

While studies that have directly examined what predicts the reporting of online risks are rare, it seemed reasonable to suppose that older children would report risks less often to adults, and more often (at least relatively speaking) to friends. Levels of reporting were not 
Running head: YOUNG ADOLESCENTS' REPORTING OF ONLINE RISKS

expected to vary with gender (at least after controlling for levels of risk exposure), but were expected to vary with extraversion, especially for reporting to friends. This led to the following set of hypotheses:

H3: Age negatively influences the reporting of online risks to adults (H3A), but positively influences their reporting to friends $(H 3 B)$, while extraversion positively influences both (H3C).

I treated online conflicts as a separate phenomenon from online risks in general, since they are essentially dyadic interactions that can be initiated by either party. Several studies both of cyberbullying and of offline conflicts (whether with peers, siblings or parents) have shown that children's conflicts tend to peak in early adolescence. We therefore expected that the level of online conflicts would increase between the 7th-grade and 9th-grade students in our sample. Research is inconclusive on whether girls or boys engage in more conflicts online, so we made no specific prediction in this area. Almost by definition, however, agreeable individuals can be expected to engage in fewer conflicts. Thus: H4: Age positively influences (H4A) and agreeableness negatively influences $(H 4 B)$ the frequency of online conflicts, both with individuals who are also known offline and those who are not.

Finally, evidence suggests that girls are more prone to worry about online risks, since they are in many ways more vulnerable to them. Neurotic individuals can also be expected to worry more about risk in general, again almost by definition. I made no specific predictions about age in this area, since children's increased exposure to online risks with age might be offset by their increasing confidence and independence. The corresponding hypothesis was: H5: Female gender (H5A) and neuroticism (H5B) positively influence the degree to which individuals worry about online risks. 
In addition, the variables relating to internet use and risk were hypothesized to correlate together, with internet use affecting risk exposure, affecting both risk vulnerability and online conflict, affecting risk reporting and risk concern. A summary of the hypothesized relationships is shown in Figure 1 below.

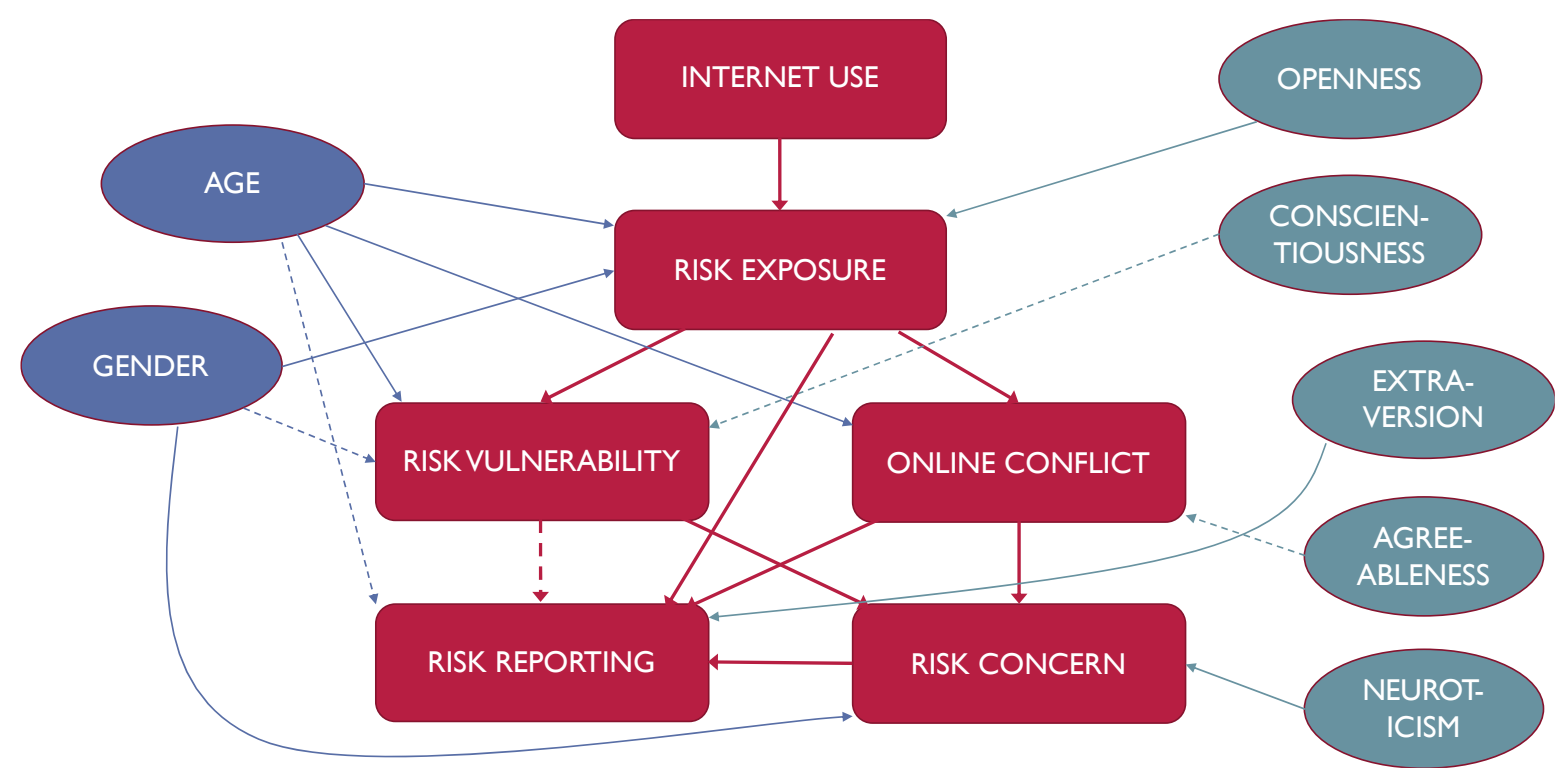

Figure 1. Process model showing hypothesized relationships between internet use variables and external variables.

\section{Method}

\section{Participants}

Two hundred and thirty-eight young people participated in the study. After exclusions for problems with internet access or other reasons for not completing the online, questionnaire, data from 193 young people (52\% female, $44 \%$ male, $4 \%$ preferred not to say), in two age groups, participated in the study. The younger group consisted of 83 seventh-grade students $(M=12.8$, min. $=11.8$, max. $=15.4$ years $)$ while the older group consisted of 93 ninth-grade students $(M=15.0, \min .=13.3$, max. $=18.0$ years $)$. 
Running head: YOUNG ADOLESCENTS' REPORTING OF ONLINE RISKS

Participants were recruited at two public secondary schools in different areas of Bogotá, Colombia, both serving mainly low-to-middle-income working families (public secondarylevel education in Bogotá is almost exclusively used by families with below the mean household income). There were no significant correlations between age, gender and school attended. The research procedures were approved by the Institutional Review Board at [blinded].

\section{Materials}

Both the original Spanish version and an English translation of the questionnaire are available in the Supplementary Materials. The same questionnaire was used for all participants. After a few demographic questions (grade, birth date, and gender) an introductory section asked how they accessed the Internet (by cellphone, tablet, or fixed or portable computer), and the typical activities that they carried out online (including chatting with friends or family, studying or searching for information, playing games, and watching

or listening to entertainment). Then, they were asked about risky requests for access (Facebook "friendship", full name, telephone number, home address, real-life meeting, or personal photos) from strangers online, as well as how they generally responded to such requests. The next section asked how often they were sent risky material (explicit photos, threats of violence, or rude messages) by strangers online. They were also asked how frequency of conflicts or arguments online, both with people they knew offline and people they did not. The following section asked participants how often they communicated disturbing behavior by a stranger online to three groups of people (adult family members, friends or non-adult family members, and teachers or other school staff). They were also asked about the sorts of information they would or would not tell to others. After a question on how worried they were in general about the risks of using the Internet, the final section 
was a Spanish-language version of the TIPI short personality questionnaire (Gosling, Rentfrow, \& Swann, 2003).

\section{Procedure}

Opt-out informed consent was obtained from all participants by means of a letter sent to parents, and those few young people whose parents said they did not wish to take part were given an alternative activity by their teacher. Written informed consent was also obtained from the young people themselves. Questionnaires were administered to groups of 20-30 students at a time according to their normal class membership and classrooms. At one school, the internet connection repeatedly failed and most of the questionnaires were therefore delivered on paper; at the other school, most were delivered online, but since there were sometimes more students than computers in the room, a few were delivered on paper. Although they completed the tasks in groups, students were instructed to maintain silence and avoid looking at their neighbors' answers, and a research assistant was present at all times to ensure that these rules were followed (they generally were). Questionnaires were always completed in the order described in the "Materials" subsection above.

\section{Plan of Analysis}

Internet use was computed as the maximum value obtained in asking about the frequency of using different methods to access the Internet. However, this measure showed a very strong ceiling effect, with the mode, median and even the mean (rounded up) being equal to the maximum possible value. Internet use was therefore eliminated from the plan of analysis and does not appear in the analyses reported in the Results section. Exploratory factor 
analysis was carried out to check that the novel questions (i.e., excluding the personality questionnaire) clustered into the sections proposed for them. Regression analyses of risk exposure, risk vulnerability, risk reporting, and risk concern were used to test the specific relationships between these variables in the process model, as well as the hypotheses relating to age, gender, and personality. School grade was also tested but was predicted to follow an identical pattern to age.

\section{Results}

\section{Descriptive statistics}

The means for the six main constructs in the study (see Figure 1), divided into groups by gender and school grade, are shown in Table 1. Means for the personality variables appear in Table 2. Correlations between the six constructs relating to internet use are shown in Table 3, and correlations between demographic and personality variables in Table 4 (the relationships between the two sets of constructs are examined in the remaining subsections of the Results section, using regression analyses). 
Running head: YOUNG ADOLESCENTS' REPORTING OF ONLINE RISKS

Table 1. Mean of various categories of online risk, split by school grade and gender (standard error of mean in parentheses)

\begin{tabular}{|c|c|c|c|c|c|c|}
\hline Grade & Gender & $\begin{array}{c}\text { Risk } \\
\text { Exposure }\end{array}$ & $\begin{array}{c}\text { Risk } \\
\text { Vulnerability }\end{array}$ & $\begin{array}{c}\text { Risk } \\
\text { of Conflict }\end{array}$ & $\begin{array}{c}\text { Risk } \\
\text { Reporting }\end{array}$ & $\begin{array}{c}\text { Risk } \\
\text { Concern }\end{array}$ \\
\hline \multirow[t]{2}{*}{$\begin{array}{l}7 \text { th } \\
\text { grade }\end{array}$} & Female & $\begin{array}{c}1.78 \\
(0.14)\end{array}$ & $1.37(0.11)$ & $\begin{array}{l}2.05 \\
(0.15)\end{array}$ & $\begin{array}{r}3.20 \\
(0.15)\end{array}$ & $\begin{array}{r}4.26 \\
(0.24)\end{array}$ \\
\hline & Male & $\begin{array}{c}1.34 \\
(0.06)\end{array}$ & $1.23(0.09)$ & $\begin{array}{c}1.54 \\
(0.12)\end{array}$ & $\begin{array}{r}3.55 \\
(0.20)\end{array}$ & $\begin{array}{r}4.89 \\
(0.32)\end{array}$ \\
\hline \multirow[t]{2}{*}{$\begin{array}{l}\text { 9th } \\
\text { grade }\end{array}$} & Female & $\begin{array}{c}2.14 \\
(0.13)\end{array}$ & $1.56(0.09)$ & $\begin{array}{c}2.53 \\
(0.15)\end{array}$ & $\begin{array}{r}3.14 \\
(0.14)\end{array}$ & $\begin{array}{r}4.55 \\
(0.23)\end{array}$ \\
\hline & Male & $\begin{array}{c}1.81 \\
(0.12)\end{array}$ & $1.60(0.10)$ & $\begin{array}{c}2.23 \\
(0.16)\end{array}$ & $\begin{array}{r}2.60 \\
(0.18)\end{array}$ & $\begin{array}{r}3.69 \\
(0.26)\end{array}$ \\
\hline
\end{tabular}

Table 2. Descriptive statistics of personality variables

\begin{tabular}{llccccc} 
Gender & Grade & $\begin{array}{c}\text { Open } \\
\text {-ness }\end{array}$ & $\begin{array}{c}\text { Conscient } \\
\text {-iousness }\end{array}$ & $\begin{array}{c}\text { Extra } \\
\text {-version }\end{array}$ & $\begin{array}{c}\text { Agreeable- } \\
\text { ness }\end{array}$ & $\begin{array}{c}\text { Neurotic } \\
\text {-ism }\end{array}$ \\
\hline \multirow{2}{*}{ Female } & 7th & 4.44 & 4.63 & 4.26 & 4.61 & 3.93 \\
& 9 th & 4.33 & 4.20 & 4.15 & 4.06 & 4.31 \\
Male & 7th & 4.64 & 4.78 & 4.14 & 4.68 & 3.49 \\
& 9 th & 3.90 & 4.29 & 3.87 & 4.29 & 3.90 \\
\multirow{2}{*}{ Female } & 7th & 0.193 & 0.212 & 0.184 & 0.228 & 0.246 \\
\multirow{2}{*}{ Male } & 9 th & 0.236 & 0.250 & 0.235 & 0.251 & 0.219 \\
& 7th & 0.268 & 0.269 & 0.236 & 0.278 & 0.277 \\
& 9 th & 0.251 & 0.232 & 0.257 & 0.214 & 0.242 \\
\hline
\end{tabular}


Running head: YOUNG ADOLESCENTS' REPORTING OF ONLINE RISKS

Table 3. Correlation matrix for the various categories of online risk.

\begin{tabular}{|c|c|c|c|c|c|}
\hline & $\begin{array}{c}\text { Risk } \\
\text { exposure }\end{array}$ & $\begin{array}{c}\text { Risk } \\
\text { vulnerability }\end{array}$ & $\begin{array}{l}\text { Risk of } \\
\text { conflict }\end{array}$ & $\begin{array}{c}\text { Risk } \\
\text { reporting }\end{array}$ & $\begin{array}{c}\text { Risk } \\
\text { concern }\end{array}$ \\
\hline \multirow[t]{2}{*}{$\begin{array}{l}\text { Risk } \\
\text { exposure }\end{array}$} & - & .637 & $.646 * * *$ & -.115 & -.004 \\
\hline & - & $(<.001)$ & $(<.001)$ & $(.130)$ & $(.963)$ \\
\hline \multirow[t]{2}{*}{$\begin{array}{l}\text { Risk } \\
\text { vulnerability }\end{array}$} & $.637 * * *$ & - & $.501 * * *$ & -.119 & -.031 \\
\hline & $(<.001)$ & - & $(<.001)$ & $(.120)$ & $(.693)$ \\
\hline \multirow[t]{2}{*}{$\begin{array}{l}\text { Risk of } \\
\text { conflict }\end{array}$} & $.646^{* * *}$ & $.501 * * *$ & - & $-.208 * *$ & $-.159 *$ \\
\hline & $(<.001)$ & $(<.001)$ & 一 & .006 & $(.039)$ \\
\hline \multirow[t]{2}{*}{$\begin{array}{l}\text { Risk } \\
\text { reporting }\end{array}$} & -.115 & -.119 & $-.208 * *$ & - & $.346 * * *$ \\
\hline & $(.130)$ & .120 & $(.006)$ & - & $(<.001)$ \\
\hline \multirow[t]{2}{*}{ Risk concern } & -.004 & -.031 & $-.159 *$ & $.346 * * *$ & - \\
\hline & $(.963)$ & .693 & $(.039)$ & $(<.001)$ & - \\
\hline
\end{tabular}


Table 4. Correlation matrix for the personality and demographic variables used in the study.

\begin{tabular}{lcrcrc} 
& Openness & $\begin{array}{c}\text { Conscient } \\
\text {-iousness }\end{array}$ & $\begin{array}{c}\text { Extra } \\
\text {-version }\end{array}$ & $\begin{array}{l}\text { Agreeable } \\
\text {-ness }\end{array}$ & $\begin{array}{c}\text { Neurotic } \\
\text {-ism }\end{array}$ \\
\hline $\begin{array}{l}\text { Openness } \\
\text { Conscient }\end{array}$ & - & $.318 * * *$ & $.446 * * *$ & $.228 * *$ & -.069 \\
-iousness & $.318 * * *$ & - & $.251 * *$ & $.470 * * *$ & $-.276^{* * *}$ \\
Extraversion & $.446 * * *$ & $.251 * *$ & - & .092 & .083 \\
Agreeableness & $.228 * *$ & $.470 * * *$ & .092 & - & $.422 * * *$ \\
Neuroticism & -.069 & $-.276 * * *$ & .083 & $-.422 * * *$ & - \\
\hline
\end{tabular}

\section{Factor analyses}

For the exploratory factor analysis of the questionnaire items relating to online risks, the minimum residual extraction method was used in combination with an oblimin rotation. Comparing these factor loadings with the path model set out in Figure 1 shows that the items in the exploratory factor analysis separated well into factors of risk exposure (Factor 1), risk vulnerability (Factor 2) and risk reporting (Factor 3). (A table of the specific questions asked, categorized with the constructs they were intended to measure, is provided in the Supplementary Materials.) However, the two items intended to measure risk of conflict (Q45_1 and Q45_2) loaded onto the same factor as the risk exposure items. Consequently, these items were combined into the latter factor to simplify the model. 
Running head: YOUNG ADOLESCENTS' REPORTING OF ONLINE RISKS

Table 5. Factor Loadings and uniqueness of the questionnaire items relating to online risks

\begin{tabular}{|c|c|c|c|c|}
\hline & \multicolumn{3}{|c|}{ Factor } & \multirow[b]{2}{*}{ Uniqueness } \\
\hline & 1 & 2 & 3 & \\
\hline Q23_1 & 0.433 & & -0.381 & 0.465 \\
\hline Q23_2 & & & & 0.756 \\
\hline Q26_1 & 0.685 & & & 0.525 \\
\hline Q26_2 & & 0.488 & & 0.510 \\
\hline Q27_1 & 0.783 & & & 0.286 \\
\hline Q27_2 & & 0.493 & & 0.432 \\
\hline Q28_1 & 0.594 & & & 0.526 \\
\hline Q28_2 & & 0.724 & & 0.531 \\
\hline Q29_1 & 0.800 & & & 0.281 \\
\hline Q29_2 & & 0.549 & & 0.438 \\
\hline Q30_2 & 0.705 & & & 0.469 \\
\hline Q30_3 & 0.723 & & & 0.550 \\
\hline Q30_4 & 0.702 & & & 0.542 \\
\hline Q30_5 & 0.649 & & & 0.629 \\
\hline Q47_1 & 0.880 & & & 0.225 \\
\hline Q47_2 & & 0.840 & & 0.352 \\
\hline Q36_1 & & & 0.785 & 0.373 \\
\hline Q36_2 & & & 0.588 & 0.596 \\
\hline Q36_3 & & & 0.575 & 0.692 \\
\hline Q45_1 & 0.699 & & & 0.497 \\
\hline Q45_2 & 0.396 & & & 0.714 \\
\hline
\end{tabular}


Running head: YOUNG ADOLESCENTS' REPORTING OF ONLINE RISKS

\section{Exposure to risks}

Against my hypothesized relationship, there was no significant correlation between risk exposure and openness to experience $(r=.106, p=.174)$. However, as predicted, females $(M=2.02, S D=0.91)$ were more likely than males $(M=1.64, S D=0.68)$ to be exposed to risks online (Welch's $t[170]=3.10, p=.002)$, and ninth-graders $(M=2.06, S D=0.85)$ were more likely than seventh-graders $(M=1.63, S D=0.77 ; t[173]=3.56, p<.001)$. There was also a significant correlation between physical age and this measure, $r=.356, p$ $<.001$. Additionally, risk exposure was found to have unpredicted, though fairly small correlations with extraversion $(r=.203, p=.008)$ and neuroticism $(r=.191, p=.014)$. In the regression model, school grade was not a significant predictor $(t=0.42, p=$ .674) once age was included, and it was therefore excluded from the reduced model without significantly affecting the variance explained. The reduced model significantly explained a medium-to-large proportion of the variance in exposure to risks, $R 2=.245, F(4,154)=$ $12.5, p<.001$. However, the full model including the other four personality variables explained significantly more of the variance, $\Delta R_{2}=.061, F(4,149)=3.31, p=.012$. 
Running head: YOUNG ADOLESCENTS' REPORTING OF ONLINE RISKS

Table 6. Regression model of predictors of risk exposure (full model). Variables marked with $*$ are those that were not predicted to have an effect.

\begin{tabular}{lcccc}
\hline \multicolumn{1}{c}{ Predictor } & $\boldsymbol{B}$ & SE & $\boldsymbol{t}$ & $\boldsymbol{p}$ \\
\hline Gender & & & & \\
$\quad$ (Female - Male) & 0.49 & 0.11 & 4.35 & $<.001$ \\
Age in years & 0.20 & 0.04 & 5.30 & $<.001$ \\
Openness & 0.04 & 0.04 & 0.87 & .387 \\
Extraversion* & 0.09 & 0.04 & 2.20 & .029 \\
Neuroticism* & 0.08 & 0.04 & 2.18 & .031 \\
Conscientiousness* & -0.04 & 0.04 & -0.88 & .382 \\
Agreeableness* & 0.09 & 0.04 & 2.11 & .036 \\
\hline
\end{tabular}

\section{Vulnerability to risks}

There was a strong correlation between risk exposure and risk vulnerability, $r=.648, p<$ .001 . The latter also correlated with age, $r=.314, p<.001$, showing a significant increase between 7 th grade $(M=1.31, S D=0.64)$ and 9 th grade $(M=1.58, S D=0.61 ; t[172]=2.87$, $p=.005, d=0.44)$. Again, age in years was a better predictor than school grade, and so the latter was omitted from the model. Gender, on the other hand, had no significant effect, $M_{\text {girls }}=1.47, S D_{\text {girls }}=0.67, M_{\text {boys }}=1.43, S D_{\text {boys }}=0.60, t=0.42, p=.672$, and nor did conscientiousness, $r=-.081, p=.301$. The reduced model significantly explained the variance in risk vulnerability, $R 2=.396, F(4,153)=25.1, p<.001$. Since the full model did not explain any more variance, $\Delta R 2=.006, F(4,149)=0.35, p=.844$, only the hypothesized predictors in the reduced model are presented below: 
Running head: YOUNG ADOLESCENTS' REPORTING OF ONLINE RISKS

Table 7. Regression model of predictors of risk vulnerability (acting on risk) - reduced model.

\begin{tabular}{llclc}
\hline \multicolumn{1}{c}{ Predictor } & $\boldsymbol{B}$ & SE & $\boldsymbol{t}$ & $\boldsymbol{p}$ \\
\hline Risk exposure & 0.44 & 0.05 & 8.57 & $<.001$ \\
Age in years & 0.04 & 0.03 & 1.44 & .151 \\
Gender: & & & & \\
$\quad$ (Female - Male) & -0.12 & -0.08 & -1.56 & .121 \\
Conscientiousness & -0.01 & 0.02 & -0.53 & .596 \\
\hline
\end{tabular}

\section{Concern about risks}

The single-item measure of risk concern correlated neither with exposure to risk $(r=-.036$, $p=.643)$, vulnerability to risk $(r=-.051, p=.520)$ nor neuroticism $(r=-.031, p=.693)$, and showed no significant effect of gender, $t(167)=0.58, p=.565, M$ female $=4.41, S D_{\text {female }}$ $=1.61, M_{\text {male }}=4.26, S D_{\text {male }}=1.84$. Unsurprisingly, the reduced model including these four variables as predictors did not significantly explain variation in risk concern, $R_{2}=.007$, $F(4,151)=0.26, p=.906$, and neither did the full model containing all the study variables, $R_{2}=.029, F(10,145)=0.44, p=.926$.

\section{Reporting of risks}

The negative correlation between exposure to risks and reporting of risks approached significance, $r=-.142, p=.062$, but there was no significant correlation between reporting of risks and vulnerability to risks, $r=-.119, p=.120$. There was however a stronger correlation with concern about risks, $r=.346, p<.001$. As predicted, there was a negative correlation (although a weak one) between reporting of risks in general and age in years $(r=-.157, p=.008)$, which could also be seen in a significant difference 
Running head: YOUNG ADOLESCENTS' REPORTING OF ONLINE RISKS

$(t[172]=2.71, p=.007, d=0.41)$ between risk reporting in 7 th grade $(M=3.36, S D=1.14)$ and 9 th grade $(M=2.90, \mathrm{SD}=1.09)$. There was no significant gender difference in reporting (Welch's $t[144]=0.64, p=.521, M_{\text {girls }}=3.17, S D_{\text {girls }}=1.02, M_{\text {boys }}=3.05, S D_{\text {boys }}$ $=1.27$ ). There was a weak correlation between reporting and extraversion, $r=.165, p=$ .032. Unpredicted correlations were found between reporting and conscientiousness, $r=$ $.207, p=.007$, and negatively with neuroticism, $r=-.171, p=.028$. However, these effects, along with that of school grade, were not significant for the betas of these variables in the full model, which did not significantly improve on the variance explained by the reduced model, $\Delta R_{2}=.034, F(5,149)=1.15, p=.337$. Since the $F$ test for the reduced model itself was significant, $R_{2}=.074, F(3,154)=4.07, p=.008$, only the hypothesized predictors are reported below.

Table 8. Regression model of predictors of reporting of risk (reduced model).

\begin{tabular}{lllll}
\hline \multicolumn{1}{c}{ Predictor } & $\boldsymbol{B}$ & SE & $\boldsymbol{t}$ & $\boldsymbol{p}$ \\
\hline Exposure to risk & -0.18 & 0.14 & -1.30 & .197 \\
Vulnerability to risk & -0.12 & 0.19 & -0.64 & .525 \\
Age_years & -0.08 & 0.06 & -1.23 & .222 \\
Extraversion & 0.13 & 0.06 & 2.21 & .029 \\
\hline
\end{tabular}

However, the hypotheses for this dependent variable were phrased in terms of differential effects of age on reporting to parents, teachers and peers. Supporting these hypotheses, age had a stronger correlation with reporting to parents or other adult family members $(r=-.288, p<.001)$ and to teachers or other school staff $(r=-.268, p<.001)$ than with reporting in general, while there was no correlation at all between age and reporting to peers $(r=-.001, p=.989)$. Descriptive statistics for the three questions on reporting risks, 
Running head: YOUNG ADOLESCENTS' REPORTING OF ONLINE RISKS

split by grade and gender, are shown below:

Table 9. Descriptive statistics for reporting of online risks to different categories of people, according to school grade and gender of participants.

\begin{tabular}{llccc} 
Grade & Gender & $\begin{array}{c}\text { Reporting to } \\
\text { parents }\end{array}$ & $\begin{array}{c}\text { Reporting to } \\
\text { teachers }\end{array}$ & $\begin{array}{c}\text { Reporting to } \\
\text { peers }\end{array}$ \\
\hline $\begin{array}{l}\text { 7th } \\
\text { grade }\end{array}$ & Female & 3.87 & 2.41 & 3.18 \\
& Male & 4.14 & 3.19 & 3.22 \\
$\begin{array}{l}\text { 9th } \\
\text { grade }\end{array}$ & Female & 3.61 & 1.85 & 3.65 \\
& Male & 2.88 & 1.85 & 3.02 \\
7 th \\
grade
\end{tabular}

\section{Discussion and conclusion}

A simplified model of the study variables, including only those that had significant correlations with other variables, is presented in Figure 2. 
Figure 2. Significant relationships found between the study variables.

$(* p<.05 ; \quad * * p<.01 ; \quad * * * p<.001)$

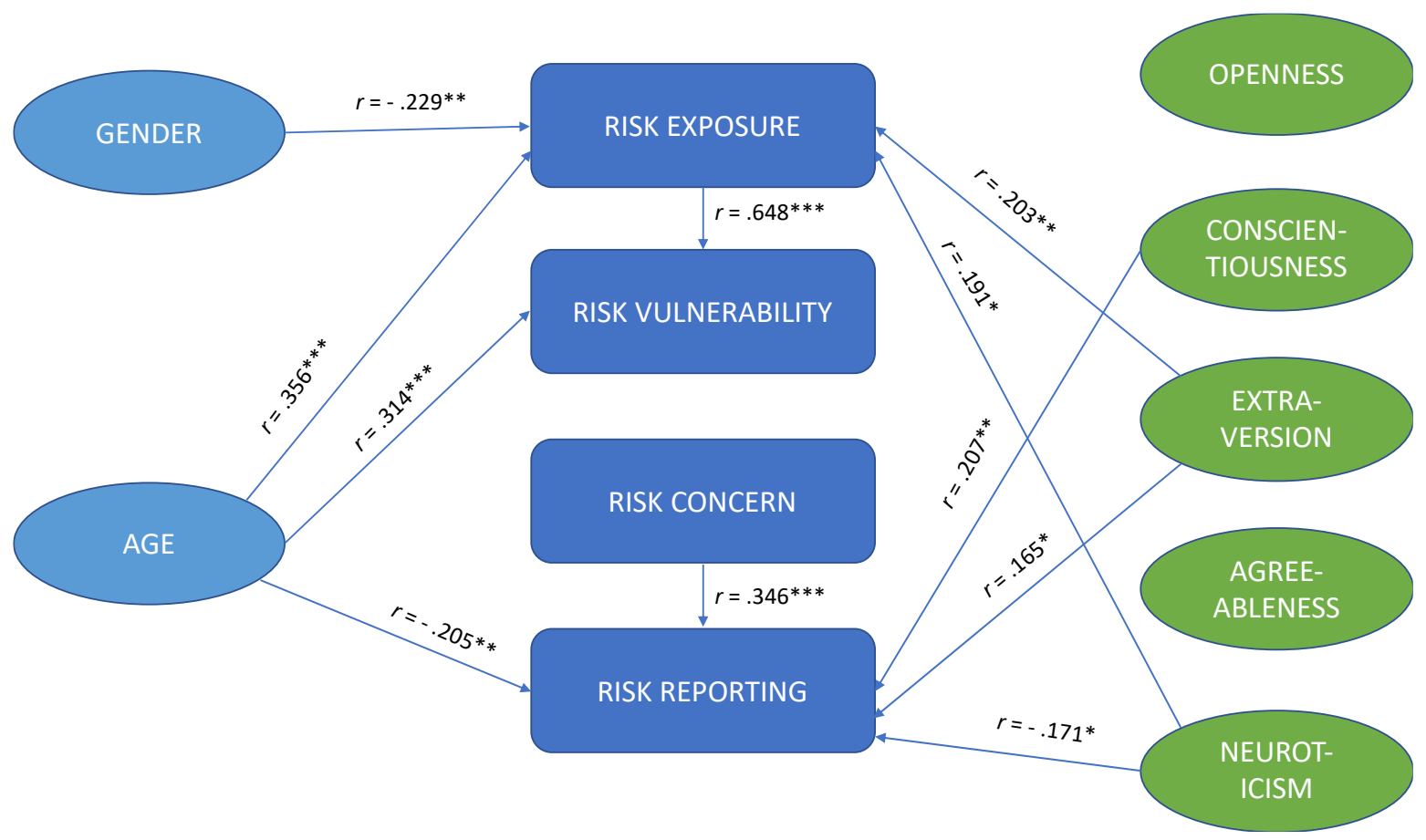

An exploratory factor analysis indicated a satisfactory degree of independence between the questions designed to find out about exposure to risks, vulnerability to (acting on) risks, concern about risks and reporting of risks. Engagement in online conflict was not found to be separable from vulnerability to risk, however, and so the scores for these items were combined with the latter to give an overall measure of vulnerability. As mentioned in the "Plan of Analysis" section above, internet use suffered from a very strong ceiling effect (since almost all children, even in this fairly low-SES context, accessed the internet several times a day) and was not included Future studies should consider more sophisticated ways of measuring total internet use, such as with diary questions, randomized time sampling, or a smartphone app. They could also pursue whether different types of internet usage may be associated with different degrees of exposure and vulnerability to risk. Regarding the 
Running head: YOUNG ADOLESCENTS' REPORTING OF ONLINE RISKS

personality variables, openness and agreeableness did not correlate with any other variables in the study and are therefore excluded from this discussion as well. It is possible that a better measure of engagement in online conflict might confirm the hypothesized relationship with agreeableness; however, there was no support in the current study for the hypothesized link between exposure to online risk and openness to experience.

There was a strong correlation between exposure to online risks and vulnerability to the same. There are several possible reasons for this. It could be that with more exposure to risks, young people become "desensitized" to them, and are more likely to (for example) click on a link containing troublesome material, or provide their personal details to strangers. It could also be the case that people who are more vulnerable to risks actively seek out exposure to them (or to material associated with them). Finally, the link could be a methodological artefact, if those participants who were more likely to say that they were exposed to risks were also more likely to say that they were more likely to respond to them, interpreting the question as one of frequency (against this interpretation, note that risk exposure did not correlate with the similarly worded questions about risk concern and risk reporting). Another interesting finding is that age and (weakly) female gender, extraversion and neuroticism all correlated with risk exposure, but that none of these correlated with risk vulnerability once risk exposure was controlled for. Thus, risk exposure appears to mediate the relationship between age and risk vulnerability (note that these variables did show a positive correlation before the regression analysis), suggesting tentatively that older adolescents' greater susceptibility to online risks may be less to do with developmental factors and more to do with desensitization.

Surprisingly, there was no link in this study between either exposure or vulnerability to online risks and concern about these risks. Risk reporting was the only study variable with 
which risk concern correlated significantly. Leaving out risk reporting (which a priori seems more likely to be causally predicted by risk concern than a predictor of it), all other variables in the study put together explained less than $3 \%$ of the variance in risk concern. The current study thus leaves a huge explanatory gap in accounting for what makes young adolescents more or less concerned about online risks. Since this does not seem to be linked to demographic or personality factors, nor exposure or vulnerability to risks, one candidate explanatory factor would be peer attitudes to these risks: whether the adolescent's friends see them as harmless fun or something to be avoided. Another would be the level and quality of education that adolescents have received about online risks: hypothetically, they might well be more worried about risks if they have unanswered questions about them. Future work could study the relationships between levels of concern and the communication that adolescents have received about risks, and integrate that with a study of adolescents' own reporting of risks. As well as being related to risk concern, the latter activity declined with age (in terms of reporting to parents and teachers, though not to peers) and was weakly correlated with conscientiousness, extraversion and (negatively) with neuroticism. These relationships should all be borne in mind when designing interventions to promote young people's communication about online risks.

The current study was an exploratory one and its major limitations were the low sample size, along with a lack of diversity in the participant population (students at two high schools in Bogotá, Colombia). This was a particular problem for the confirmatory factor analysis: the fact that this failed to confirm the factor structure of the questionnaire was probably due to limitations of power, since the exploratory factor analysis found a similar solution based around the four factors of risk exposure, risk vulnerability, risk concern and risk reporting. Despite the low power, numerous significant relationships were uncovered 
in the data, the majority remaining significant with an alpha level of .01 and several remaining so even with alpha at .001 . It would thus be worthwhile replicating this questionnaire with a larger sample size and a culturally diverse population to see if the same relationships apply.

Given the difficulties in today's "always-on" internet environment of measuring frequency of internet use with simple survey questions, improvements to the method of measuring frequency of internet use (for example, using a diary method, time-sampling push notifications, or a time monitoring app) need to be made in order to use this variable as a predictor of online risk exposure. The same goes for the measurement of online conflict: a more sophisticated approach would be to have several questions for each type of online risk, so as to develop sub-scales within the measures of risk exposure, risk vulnerability, risk concern and risk reporting, and relate these to external variables. On the subject of these external variables, the measures of personality could be improved from the miniature two-item scales used in the current study, which (along with increasing the power) might lead to stronger results than the various weak correlations with personality found here.

Nevertheless, the current study is valuable for its conceptualization of risk-related activity as a process, or rather two processes, that vary in interesting ways through adolescence (with risk exposure strongly predicting risk vulnerability and risk concern strongly predicting risk reporting, and both exposure and reporting showing significant, independent relationships with age). Future research should focus on uncovering drivers of risk concern, since these were entirely absent in the current study, yet risk concern was shown to be an important predictor of risk reporting. A focus on how young people communicate about online risks may help to uncover why some are more concerned than 
Running head: YOUNG ADOLESCENTS' REPORTING OF ONLINE RISKS

others, and possibly even help to develop interventions which alleviate their concerns and improve their general wellbeing.

\section{References}

Antoniadou, N., \& Kokkinos, C. M. (2015). Cyber and school bullying: Same or different phenomena? Aggression and Violent Behavior, 25, 363-372.

Baumgartner, S. E., Valkenburg, P. M., \& Peter, J. (2010). Unwanted online sexual solicitation and risky sexual online behavior across the lifespan. Journal of Applied Developmental Psychology, 31, 439-447.

Bayraktar, F., Barbovschi, M., \& Kontrikova, V. (2016). Risky sociability and personal agency-offline meetings with online contacts among European children and adolescents. Children and Youth Services Review, 70, 78-83.

Beyens, I., Vandenbosch, L., \& Eggermont, S. (2015). Early adolescent boys' exposure to Internet pornography: Relationships to pubertal timing, sensation seeking, and academic performance. Journal of Early Adolescence, 35, 1045-1068.

Cabello-Hutt, T., Cabello, P., \& Claro, M. (2018). Online opportunities and risks for children and adolescents: The role of digital skills, age, gender and parental mediation in Brazil. New Media and Society, 20, 2411-2431.

Gámez-Guadix, M., \& De Santisteban, P. (2018). “Sex pics?”: Longitudinal predictors of sexting among adolescents. Journal of Adolescent Health, 63, 608-614.

Gibb, Z. G., \& Devereux, P. G. (2014). Who does that anyway? Predictors and personality correlates of cyberbullying in college. Computers in Human Behavior, 38, 8-16.

Gosling, S. D., Rentfrow, P. J., \& Swann Jr, W. B. (2003). A very brief measure of the BigFive personality domains. Journal of Research in Personality, 37, 504-528. 
Running head: YOUNG ADOLESCENTS' REPORTING OF ONLINE RISKS

Ho, S. S., Chen, L., \& Ng, A. P. (2017). Comparing cyberbullying perpetration on social media between primary and secondary school students. Computers and Education, 109, 74-84.

Hu, J., Zhen, S., Yu, C., Zhang, Q., \& Zhang, W. (2017). Sensation seeking and online gaming addiction in adolescents: a moderated mediation model of positive affective associations and impulsivity. Frontiers in Psychology, 8, 699.

Kircaburun, K., Kokkinos, C. M., Demetrovics, Z., Király, O., Griffiths, M. D., \& Çolak, T. S. (2019). Problematic online behaviors among adolescents and emerging adults: Associations between cyberbullying perpetration, problematic social media use, and psychosocial factors. International Journal of Mental Health and Addiction, 17, 891908.

Koutamanis, M., Vossen, H. G., \& Valkenburg, P. M. (2015). Adolescents' comments in social media: Why do adolescents receive negative feedback and who is most at risk? Computers in Human Behavior, 53, 486-494.

Kuss, D. J., Van Rooij, A. J., Shorter, G. W., Griffiths, M. D., \& van de Mheen, D. (2013). Internet addiction in adolescents: Prevalence and risk factors. Computers in Human Behavior, 29, 1987-1996.

Livingstone, S., \& Görzig, A. (2014). When adolescents receive sexual messages on the internet: Explaining experiences of risk and harm. Computers in Human Behavior, 33, $8-15$.

Livingstone, S., Ólafsson, K., Helsper, E. J., Lupiáñez-Villanueva, F., Veltri, G. A., \& Folkvord, F. (2017). Maximizing opportunities and minimizing risks for children online: The role of digital skills in emerging strategies of parental mediation. Journal of Communication, 67, 82-105. 
Running head: YOUNG ADOLESCENTS' REPORTING OF ONLINE RISKS

Lu, H. Y. (2008). Sensation-seeking, Internet dependency, and online interpersonal deception. CyberPsychology and Behavior, 11, 227-231.

Mehroof, M., \& Griffiths, M. D. (2010). Online gaming addiction: The role of sensation seeking, self-control, neuroticism, aggression, state anxiety, and trait anxiety. Cyberpsychology, Behavior, and Social Networking, 13, 313-316.

Öztürk, C., Bektas, M., Ayar, D., Öztornac1, B. Ö., \& Yağc1, D. (2015). Association of personality traits and risk of internet addiction in adolescents. Asian Nursing Research, 9, 120-124.

Reardon, K. W., Wang, M., Neighbors, C., \& Tackett, J. L. (2019). The personality context of adolescent gambling: Better explained by the Big Five or sensationseeking? Journal of Psychopathology and Behavioral Assessment, 41, 69-80.

Schaeffer, K. (2019). Most U.S. teens who use cellphones do it to pass time, connect with others, learn new things. Pew Research Center. Retrieved on March 9, 2020, from https://www.pewresearch.org/fact-tank/2019/08/23/most-u-s-teens-who-usecellphones-do-it-to-pass-time-connect-with-others-learn-new-things/

Shin, W., \& Lwin, M. O. (2017). How does "talking about the Internet with others" affect teenagers' experience of online risks? The role of active mediation by parents, peers, and school teachers. New Media and Society, 19, 1109-1126.

Silver, L., Smith, A., Johnson, C., Jiang, J., Anderson, M., \& Rainie, L. (2019). Mobile connectivity in emerging economies. Pew Research Center. Retrieved on March 9, 2020, from https://www.pewresearch.org/internet/2019/03/07/mobile-connectivity-inemerging-economies/ 
Running head: YOUNG ADOLESCENTS' REPORTING OF ONLINE RISKS

Sun, S., Fan, X., \& Du, J. (2016). Cyberbullying perpetration: A meta-analysis of gender differences. International Journal of Internet Science, 11, 61-81.

Van der Aa, N., Overbeek, G., Engels, R. C., Scholte, R. H., Meerkerk, G. J., \& Van den Eijnden, R. J. (2009). Daily and compulsive internet use and well-being in adolescence: a diathesis-stress model based on big five personality traits. Journal of youth and adolescence, $38,765$.

Van Ouytsel, J., Van Gool, E., Ponnet, K., \& Walrave, M. (2014). The association between adolescents' characteristics and engagement in sexting. Journal of Adolescence, 37, $1387-1391$.

White, C. M., Gummerum, M., \& Hanoch, Y. (2018). Framing of online risk: Young adults' and adolescents' representations of risky gambles. Decision, 5, 119-128.

Wisniewski, P., Xu, H., Rosson, M. B., \& Carroll, J. M. (2017). Parents just don't understand: Why teens don't talk to parents about their online risk experiences. In Proceedings of the 2017 ACM Conference on Computer Supported Cooperative Work and Social Computing (pp. 523-540). ACM. 